\title{
Mangiferin enhances the sensitivity of human multiple myeloma cells to anticancer drugs through suppression of the nuclear factor $\kappa B$ pathway
}

\author{
TOMOYA TAKEDA ${ }^{1}$, MASANOBU TSUBAKI ${ }^{1}$, TOSHIKI KINO ${ }^{1}$, AYAKO KAWAMURA ${ }^{1}$, \\ SHOTA ISOYAMA ${ }^{1}$, TATSUKI ITOH ${ }^{4}$, MOTOHIRO IMANO $^{5}$, GENZOH TANABE ${ }^{2}$, \\ OSAMU MURAOKA ${ }^{2}$, HIDEAKI MATSUDA ${ }^{3}$, TAKAO SATOU ${ }^{6}$ and SHOZO NISHIDA ${ }^{1}$
}

${ }^{1}$ Division of Pharmacotherapy, ${ }^{2}$ Laboratory of Pharmaceutical Organic Chemistry, ${ }^{3}$ Department of Natural Drugs Resources,
Kinki University School of Pharmacy, Kowakae, Higashi-Osaka; ${ }^{4}$ Department of Food Science and Nutrition,
Kinki University School of Agriculture, Nara; Departments of ${ }^{5}$ Surgery and ${ }^{6}$ Pathology,
Kinki University School of Medicine, Osakasayama, Osaka, Japan

Received November 19, 2015; Accepted March 15, 2016

DOI: $10.3892 /$ ijo.2016.3470

\begin{abstract}
Multiple myeloma (MM) is still an incurable hematological malignancy with a 5-year survival rate of $\sim 35 \%$, despite the use of various treatment options. The nuclear factor $\kappa \mathrm{B}(\mathrm{NF}-\kappa \mathrm{B})$ pathway plays a crucial role in the pathogenesis of MM. Thus, inhibition of the $N F-\kappa B$ pathway is a potential target for the treatment of MM. In a previous study, we showed that mangiferin suppressed the nuclear translocation of $\mathrm{NF}-\kappa \mathrm{B}$. However, the treatment of MM involves a combination of two or three drugs. In this study, we examined the effect of the combination of mangiferin and conventional anticancer drugs in an MM cell line. We showed that the combination of mangiferin and an anticancer drug decreased the viability of MM cell lines in comparison with each drug used separately. The decrease in the combination of mangiferin and an anticancer drug induced cell viability was attributed to increase the expression of p53 and Noxa and decreases the expression of XIAP, survivin, and Bcl-xL proteins via inhibition of NF- $\mathrm{KB}$ pathway. In addition, the combination treatment caused the induction of apoptosis, activation of caspase- 3 and
\end{abstract}

Correspondence to: Dr Shozo Nishida, Division of Pharmacotherapy, Kinki University School of Pharmacy, Kowakae, Higashi-Osaka 577-8502, Japan

E-mail: nishida@phar.kindai.ac.jp

Abbreviations: AML, acute myeloid leukemia; Bax, B cell leukemia-2 associated X; Bcl-2, B cell leukemia-2; Bcl-xL, B cell leukemia-xL; ERK1/2, extracellular signal-regulated kinase 1/2; IAP, inhibitors of apoptosis; I $\mathrm{KB}$, inhibitor of $\kappa \mathrm{B}$; JNK1/2, c-Jun N-terminal protein kinase $1 / 2$; MM, multiple myeloma; NF- $\kappa B$, nuclear factor $\kappa \mathrm{B}$; PUMA, p53 upregulated modulator of apoptosis; XIAP, X-linked inhibitor of apoptosis protein

Key words: multiple myeloma, mangiferin, $\mathrm{NF}-\kappa \mathrm{B}$, anticancer drug, $\mathrm{p} 53$, Noxa, X-linked inhibitor of apoptosis protein, survivin, Bcl-xL the accumulation of the cells in the sub-G1 phase of the cell cycle. Our findings suggest that the combination of mangiferin and an anticancer drug could be used as a new regime for the treatment of MM.

\section{Introduction}

Multiple myeloma (MM) is a B cell malignancy characterized by clonal proliferation of plasma cells in the bone marrow (1). $\mathrm{MM}$ is the most common hematological malignancy, second only to non-Hodgkin's lymphoma and accounts for $10 \%$ of all hematological malignancies and $1 \%$ of all cancers (2). MM treatment comprises vincristine/adriamycin/dexamethasone or melphalan/prednisolone chemotherapy and novel agents such as thalidomide, lenalidomide, pomalidomide, and bortezomib $(3,4)$. However, MM remains an incurable disease with a 5 -year survival rate of $35 \%$ (5). In addition, most of the drugs used for MM treatment have side effects that limit their utility. Thus, there remains an unmet need for novel therapies for MM treatment.

The nuclear factor $\kappa \mathrm{B}(\mathrm{NF}-\kappa \mathrm{B})$ pathway plays a crucial role in the survival, growth, and drug resistance of different types of cancers, including $\mathrm{MM}(6,7)$. Constitutive $N F-\kappa B$ activity is present in human MM cell lines and cells of the MM patients (8). The NF- $\kappa$ B family includes RelA (p65), RelB, c-Rel, p50

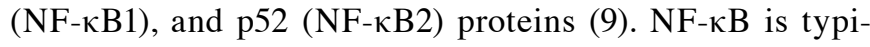
cally a heterodimer composed of p50 and p65 subunits and is constitutively present in the cytosol and the nucleus. In the cytosol, NF- $\kappa \mathrm{B}$ is inactivated by its association with inhibitor of NF- $\kappa \mathrm{B}(\mathrm{I} \kappa \mathrm{B})(10)$. Upon stimulation, I $\kappa \mathrm{B}$ is phosphorylated by $\mathrm{I} \kappa \mathrm{B}$ kinases marking it for proteasomal degradation and thereby allowing nuclear translocation of NF- $\kappa \mathrm{B}(5,11)$. Then, $\mathrm{NF}-\kappa \mathrm{B}$ binds to specific DNA sequences and promotes the transcription of its target genes (12). The NF- $\kappa \mathrm{B}$ pathway regulates the gene expression of cell cycle regulators (c-Myc, cyclin D, cyclin E, p21, and p27) and anti-apoptotic molecules [B cell leukemia 2 (Bcl-2), B cell leukemia-xL (Bcl-xL), $\mathrm{X}$-linked inhibitor of apoptosis (XIAP), and c-IAP] $(13,14)$. 
Recent studies have reported that NF- $\mathrm{NB}$ inhibitors induced apoptosis in hematopoietic tumor cells through downregulation of anti-apoptotic proteins (15). Therefore, the inhibition of $\mathrm{NF}-\kappa \mathrm{B}$ signaling is a potential target for the treatment of MM.

Recently, plant and plant-derived drugs have been recognized as one of the most attractive approaches for cancer therapy (16). In addition, many drugs derived from plants have been shown to be useful and effective in sensitizing tumors to conventional agents, prolonging survival time, and preventing the side effects of chemotherapy $(17,18)$. Mangiferin, 1,3,6,7-tetrahydroxyxanthone-C2- $\beta$-Dglucoside, is a compound extracted from plants belonging to the Anacardiaceae and Gentianaceae families, including Mangifera indica L. (19). Mangiferin has been reported to have various bioactivities, such as anti-oxidant, antitumor, antidiabetic, anti-inflammatory, and immunomodulatory activities (19). Previous studies have revealed that mangiferin has anticancer effects in acute myeloid leukemia (AML) cell lines (20). In addition, we showed that mangiferin induced apoptosis by inhibiting the nuclear translocation of NF- $\mathrm{NB}$. However, the treatment of MM involves a combination of two or three drugs, including adriamycin, vincristine, and melphalan. In this study, we examined the effect of the combination of mangiferin and conventional anticancer drugs in MM cell lines.

\section{Materials and methods}

Materials. Mangiferin $\left(\mathrm{C}_{19} \mathrm{H}_{18} \mathrm{O}_{11}\right)$ and melphalan were purchased from Sigma (St. Paul, MN, USA), and dissolved in dimethyl sulfoxide. These reagents were dissolved in phosphate-buffered saline (PBS) and filtered through $0.45-\mu \mathrm{m}$ syringe filters (Iwaki Glass, Tokyo, Japan) before use in the experiments described below.

Adriamycin and vincristine were purchased from Sigma. These reagents were dissolved in PBS and used for the various assays described below.

Cell culture. IM9 cells and RPMI8226 were obtained from Health Science Research Resources Bank (Osaka, Japan). IM9 cells were cultured in RPMI-1640 medium (Sigma) containing $10 \%$ fetal bovine serum (Gibco, Carlsbad, CA, USA), $100 \mu \mathrm{g} / \mathrm{ml}$ penicillin (Gibco), $100 \mathrm{U} / \mathrm{ml}$ streptomycin (Gibco), and $25 \mathrm{mM}$ 4-(2-hydroxyethyl)-1-piperazine ethanesulfonic acid (Wako, Osaka, Japan). All cell lines were maintained at $37^{\circ} \mathrm{C}$ in an atmosphere containing $5 \% \mathrm{CO}_{2}$.

Trypan blue exclusion assay. The cells were plated in 96-well plates at $2 \times 10^{4}$ cells $/ \mathrm{ml}$ and treated with mangiferin, anticancer drugs, a combination of both, or without mangiferin (control). After incubation, the cells were stained with trypan blue and the number of stained cells was counted at days one, three, and five.

\section{Western blotting}

Preparation of nuclear extracts for $N F-\kappa B$. The cells treated with mangiferin, anticancer drugs, a combination of both, or without mangiferin (control) were washed with cold PBS and lysed using a lysis buffer containing $100 \mathrm{mM}$ Tris- $\mathrm{HCl}$
(pH 7.4), 1 mM EDTA, $0.5 \%$ NP-40, $1 \mu \mathrm{M}$ pepstatin, $1 \mu \mathrm{M}$ leupeptin, $2 \mathrm{mM}$ sodium orthovanadate, $1 \mu \mathrm{M}$ calpain inhibitor, phosphatase inhibitor cocktail I/II, and $1 \mathrm{mM}$ phenylmethylsulfonyl fluoride (PMSF). The lysates were centrifuged at $14,000 \mathrm{rpm}$ for $5 \mathrm{~min}$, and the supernatant, which contained the cytoplasmic extracts, was stored at $-80^{\circ} \mathrm{C}$. The nuclear pellet was resuspended in cold nuclear extraction buffer for $30 \mathrm{~min}$. The extract was centrifuged at 14,000 rpm for $5 \mathrm{~min}$, and the supernatant containing the nuclear extract was obtained. The proteins were measured using the BCA protein assay kit (Pierce, Rockford, IL, USA). Total cellular proteins (30 $\mu \mathrm{g}$ of protein) from the cytoplasmic or the nuclear extract were separated using $10 \%$ sodium dodecyl sulfate (SDS) polyacrylamide gels. The proteins were transferred to polyvinyl difluoride (PVDF) membranes (Amersham, Arlington Heights, IL, USA). The membranes were blocked with $5 \%$ skim milk and incubated overnight at $4^{\circ} \mathrm{C}$ with rabbit anti-human NF- $\kappa$ B p65 (Cell Signaling Technology, Beverly, MA, USA) and rabbit anti-human lamin A/C antibodies (Santa Cruz Biotechnologies, Santa Cruz, CA, USA). After binding to an appropriate horseradish peroxidase-conjugated secondary antibody, the proteins were visualized using Luminata Forte Western HRP Substrate (Millipore, MA, USA) according to the manufacturer's instructions.

Preparation of whole cell lysates. The cells treated with mangiferin, anticancer drugs, a combination of both, or without mangiferin (control) were washed with cold PBS and lysed with a lysis buffer containing $100 \mathrm{mM}$ Tris- $\mathrm{HCl}$ (pH 7.4), $1 \mathrm{mM}$ EDTA, $0.5 \% \mathrm{NP}-40,1 \mu \mathrm{M}$ pepstatin, $1 \mu \mathrm{M}$ leupeptin, $2 \mathrm{mM}$ sodium orthovanadate, $1 \mu \mathrm{M}$ calpain inhibitor, phosphatase inhibitor cocktail I/II, and $1 \mathrm{mM}$ PMSF. The proteins were measured using the BCA protein assay kit (Pierce). The extracts (30 $\mu \mathrm{g}$ of protein) were separated using $10 \%$ SDS polyacrylamide gels. The proteins were then transferred to PVDF membranes (Amersham). The membranes were blocked with $5 \%$ skim milk and incubated overnight at $4{ }^{\circ} \mathrm{C}$ with each of the following antibodies: rabbit anti-human phospho-p44/42 mitogen-activated protein kinase (MAPK, ERK1/2), rabbit anti-human p44/42 MAPK (ERK1/2), mouse anti-human phospho-IкB, rabbit anti-human $\mathrm{I} \kappa \mathrm{B}$, rabbit anti-human phospho-stress-activated protein kinase/c-jun $\mathrm{N}$-terminal kinase (JNK1/2), rabbit anti-human JNK1/2, rabbit anti-human cyclin D, rabbit anti-human cyclin E, rabbit anti-human XIAP, rabbit anti-human survivin (Cell Signaling Technology), mouse anti-human $\beta$-actin (Sigma), rabbit anti-human p53, rabbit anti-human p21, rabbit anti-human p27, rabbit anti-human PUMA, rabbit anti-human NOXA, rabbit anti-human Bcl-xL, rabbit anti-human Bax, rabbit anti-human Bim, and rabbit antihuman Bcl-2 (Santa Cruz Biotechnologies). After binding of an appropriate horseradish peroxidase-conjugated secondary antibody, the proteins were visualized using Luminata Forte Western HRP Substrate (Millipore) according to the manufacturer's instructions.

Flow cytometry. The cells treated with mangiferin, anticancer drugs, a combination of both, or without mangiferin (control) were washed with cold PBS, and fixed in $70 \%$ ethanol. The cells were resuspended in PBS and $50 \mu \mathrm{g} / \mathrm{ml}$ propidium iodide was added. Then, the samples were measured on a BD-LSR 

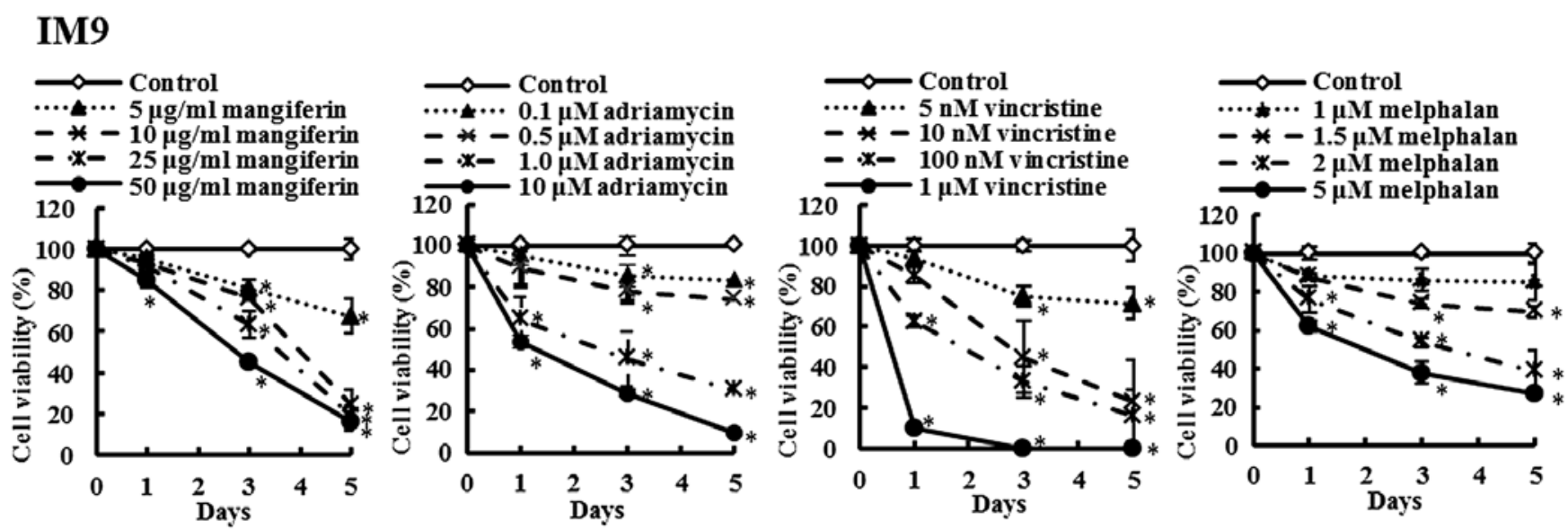

B

\section{RPMI8226}
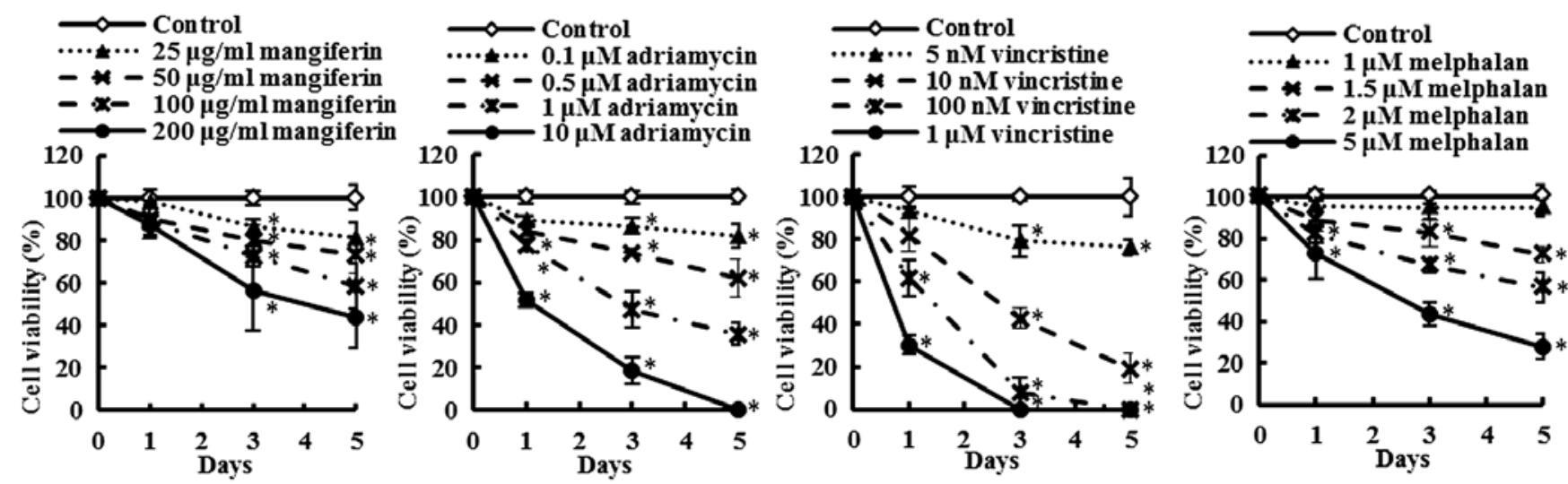

Figure 1. Mangiferin, adriamycin, vincristine, and melphalan decrease the viability of IM9 cells and RPMI8226 cells. (A) IM9 cells were treated with mangiferin $(5-50 \mu \mathrm{g} / \mathrm{ml})$, adriamycin $(0.1-10 \mu \mathrm{M})$, vincristine $(5 \mathrm{~nm}-1 \mu \mathrm{M})$, and melphalan $(1-5 \mu \mathrm{M})$. (B) RPMI8226 cells were treated with mangiferin (25-200 $\mu \mathrm{g} / \mathrm{ml})$, adriamycin (0.1-10 $\mu \mathrm{M})$, vincristine (5 nm-1 $\mu \mathrm{M})$, and melphalan (1-5 $\mu \mathrm{M})$. Then, trypan blue exclusion assay was performed in IM9 cells and RPMI8266 cells after one, three, and five days. The results are expressed as the mean \pm standard deviation (SD) of three experiments performed in triplicate. ${ }^{*} \mathrm{p}<0.05$ compared with control.

flow cytometer (BD Biosciences, CA, USA). Cell cycles were analyzed on Cell Quest software (BD Biosciences).

Analysis of apoptosis by flow cytometry. Measurement of cells undergoing apoptosis was performed with the Muse ${ }^{\mathrm{TM}}$ Annexin V and Dead Cell Assay kit (Merck Millipore, Darmstadt, Germany), according to the manufacturer's instructions. The cells were treated with mangiferin, anticancer drugs, a combination of both, or without mangiferin (control) for $48 \mathrm{~h}$. Then, Muse Annexin V and dead cell reagent was added. After incubation for $20 \mathrm{~min}$ at room temperature, apoptotic cells were applied to a Muse Cell Analyzer (Merck Millipore).

Measurement of the proteolytic activity of caspase-3. The activity of caspase-3 was determined using the caspase-3/ CPP32 fluorometric assay kit (BioVision Mountain View, CA, USA) according to the manufacturer's instructions. The cells were treated with mangiferin, anticancer drugs, a combination of both, or without mangiferin (control) for $36 \mathrm{~h}$. Then, the cells were washed in PBS and lysed using the lysis buffer provided in the kit. The cell lysates were centrifuged at $14,000 \mathrm{rpm}$ for
$5 \mathrm{~min}$, and the reaction buffer containing $1 \mathrm{mM}$ Asp-Glu-ValAsp-7-amino-4-trifluoromethylcoumarin was added to the supernatants and incubated at $37^{\circ} \mathrm{C}$ for $2 \mathrm{~h}$. Subsequently, the absorbance was measured using a fluorescence spectrophotometer (Hitachi, Tokyo, Japan) at an emission wavelength of $505 \mathrm{~nm}$ and an excitation wavelength of $400 \mathrm{~nm}$.

Statistical analysis. All results are expressed as means \pm standard deviation of several independent experiments. Multiple comparisons of the data were performed using analysis of variance with Dunnett's test. P-values $<5 \%$ were considered significant.

\section{Results}

Mangiferin, adriamycin, vincristine, and melphalan decrease the viability of the MM cell line. The effects of mangiferin and the three anticancer drugs (adriamycin, vincristine, and melphalan) on the viability of the MM cell lines (IM9 and RPMI8226) as determined by the trypan blue exclusion assay are shown in Fig. 1. IM9 cells were treated in the absence 


\section{IM9}
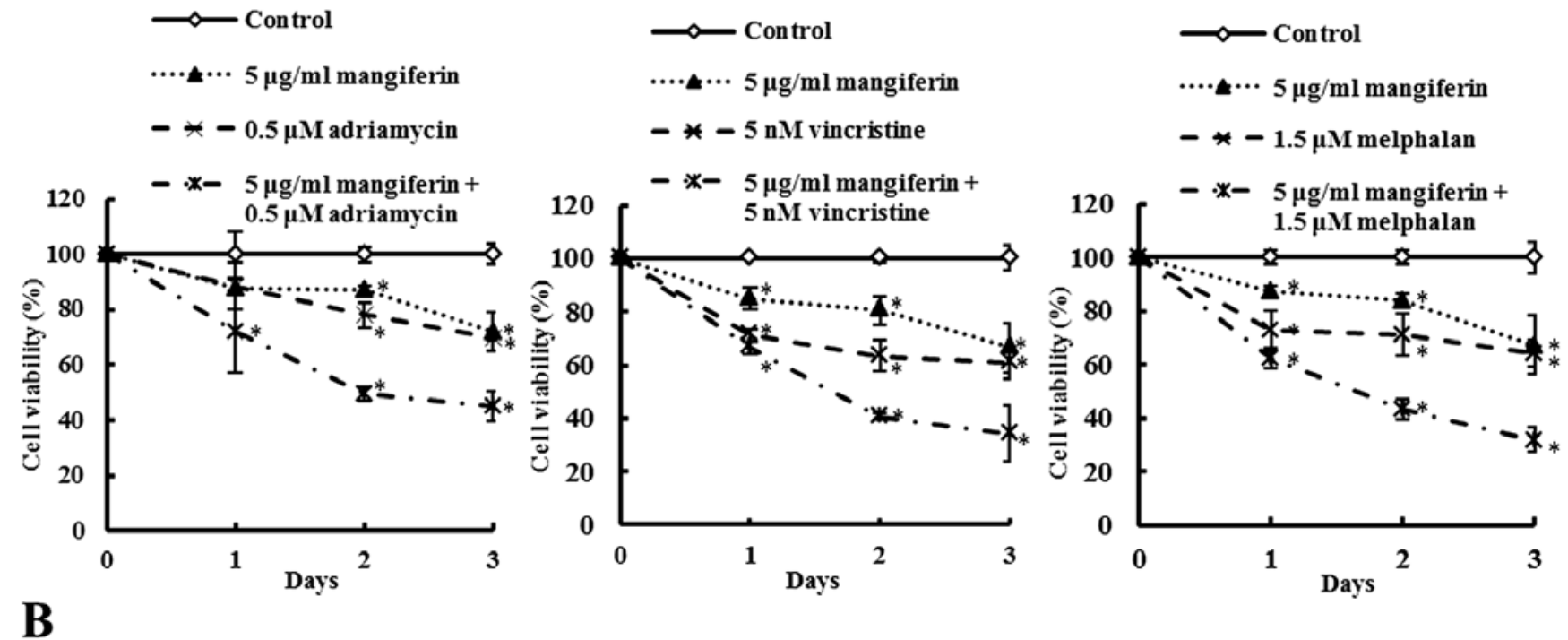

\section{RPMI8226}
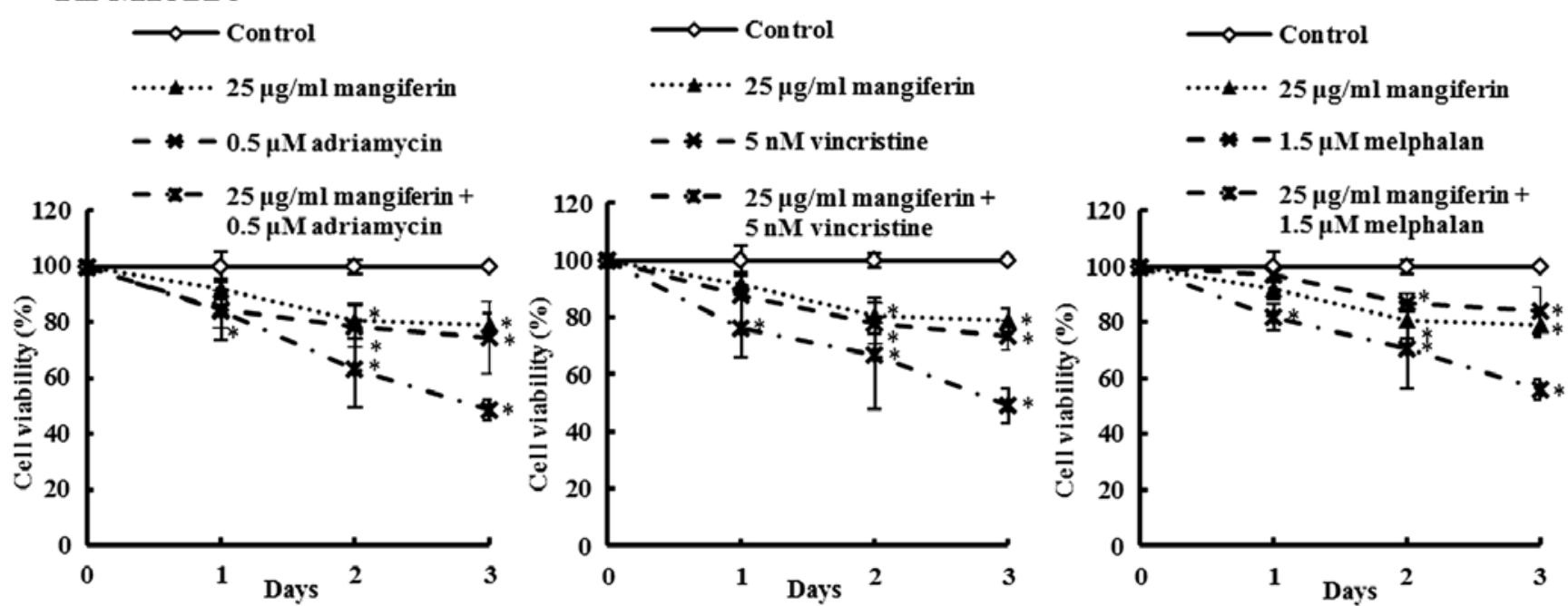

Figure 2. Mangiferin enhances the effect of anticancer drugs on MM cell lines. (A) IM9 cells were treated with mangiferin $(5 \mu \mathrm{g} / \mathrm{ml})$ or adriamycin $(0.5 \mu \mathrm{M})$, vincristine $(5 \mathrm{nM})$, and melphalan $(1.5 \mu \mathrm{M})$, or a mixture of mangiferin with an anticancer drug. (B) RPMI8226 cells were treated with mangiferin (25 $\mu \mathrm{g} / \mathrm{ml})$ or adriamycin $(0.5 \mu \mathrm{M})$, vincristine $(5 \mathrm{nM})$, and melphalan $(1.5 \mu \mathrm{M})$, or a mixture of mangiferin with an anticancer drug. Then, trypan blue exclusion assay was performed in IM9 cells and RPMI8226 cells after one, two, and three days. The results are expressed as the mean \pm standard deviation (SD) of three experiments performed in triplicate. ${ }^{*} \mathrm{p}<0.05$ compared with control.

(control) or presence of mangiferin $(5-50 \mu \mathrm{g} / \mathrm{ml})$, adriamycin (0.1-10 $\mu \mathrm{M})$, vincristine (5 nM-1 $\mu \mathrm{M})$, or melphalan (1-5 $\mu \mathrm{M})$. After three days, the viability of IM9 cells treated with 5, 10, 25 , and $50 \mu \mathrm{M}$ mangiferin was $80.5,76.3,63.3$ and $45.3 \%$, respectively, whereas that after five days was $67.2,24.5,19.3$ and $16.3 \%$, respectively. After three days, the viability of IM9 cells treated with $5,10,25$, and $50 \mu \mathrm{M}$ adriamycin was 85.5 , 78.0, 45.4 and $28.9 \%$, respectively, whereas that after five days was $83.1,74.3,30.2$ and $9.7 \%$, respectively. Vincristine and melphalan showed results similar to those observed with adriamycin. In addition, RPMI8226 cells also showed results similar to those observed with IM9 cells (Fig. 1B). These results indicated that mangiferin, adriamycin, vincristine, and melphalan decreased the viability of MM cell lines in a concentration-dependent manner.
Mangiferin enhances the sensitivity of human multiple myeloma cells to anticancer drugs. The effects of mangiferin, the three anticancer drugs, and the combination of each anticancer drug and mangiferin on the viability of the MM cell lines (IM9 and RPMI8226) were determined by trypan blue exclusion assay and are shown in Fig. 2. IM9 cells were treated with either mangiferin $(5 \mu \mathrm{g} / \mathrm{ml})$, adriamycin $(0.5 \mu \mathrm{M})$, vincristine $(5 \mathrm{nM})$, melphalan $(1.5 \mu \mathrm{M})$, or combination of mangiferin with an anticancer drug. After three days, the viability of IM9 cells treated with $5 \mu \mathrm{g} / \mathrm{ml}$ mangiferin, $0.5 \mu \mathrm{M}$ adriamycin, or combination of both was 72.0,69.8 and $45.0 \%$, respectively. The combination of mangiferin and vincristine or melphalan showed results similar to those observed with adriamycin. In addition, RPMI8226 cells also showed results similar to those observed with IM9 
A

\section{IM9}
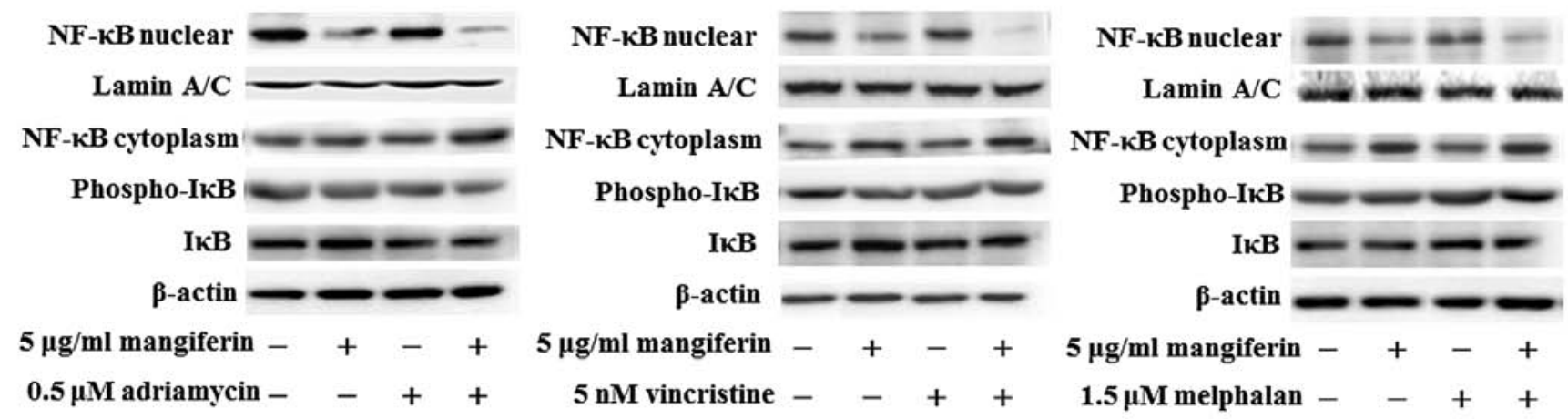

B

RPMI8226
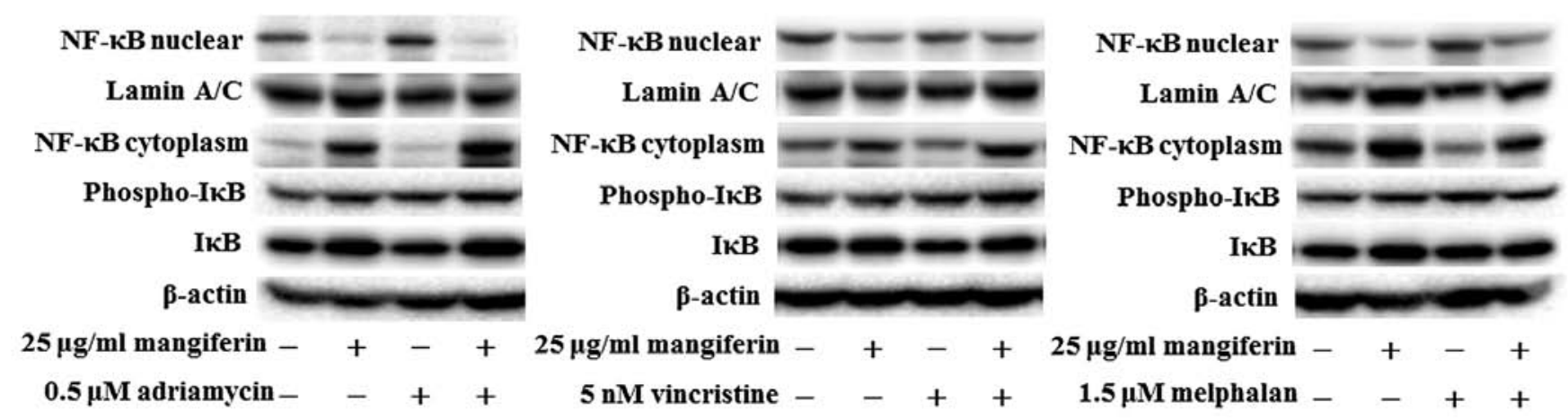

$25 \mu \mathrm{g} / \mathrm{ml}$ mangiferin -
$5 \mathrm{nM}$ vincristine $-+_{-}++_{+}$

Figure 3. The combination of mangiferin and an anticancer drug suppresses the nuclear translocation of NF- $\mathrm{\kappa B}$. (A) IM9 cells were treated with mangiferin $(5 \mu \mathrm{g} / \mathrm{ml})$ or adriamycin $(0.5 \mu \mathrm{M})$, vincristine $(5 \mathrm{nM})$, and melphalan $(1.5 \mu \mathrm{M})$, or a mixture of mangiferin with an anticancer drug for three days (B) RPMI8226 cells were treated with mangiferin $(25 \mu \mathrm{g} / \mathrm{ml})$ or adriamycin $(0.5 \mu \mathrm{M})$, vincristine $(5 \mathrm{nM})$, and melphalan $(1.5 \mu \mathrm{M})$, or a mixture of mangiferin

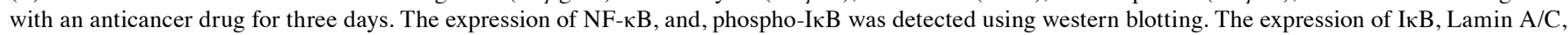
and $\beta$-actin were used as internal controls.

cells (Fig. 2B). These results show that the combination of mangiferin and an anticancer drug significantly reduced the viability of the MM cell line in comparison to the use of each of these drugs separately.

The combination of mangiferin and an anticancer drug suppresses the nuclear translocation of $N F-\kappa B$. In a previous study, we showed that mangiferin inhibits the nuclear translocation of NF- $\kappa \mathrm{B}$ in AML cell lines (20). However, mangiferin did not affect the levels of ERK1/2, Akt, and p38MAPK phosphorylation. To clarify the molecular mechanisms underlying the effects of combination of mangiferin and other anticancer drugs, we investigated the nuclear translocation of $N F-\kappa B$ and expression of phosphorylated $\mathrm{I} \kappa \mathrm{B}$ and $\mathrm{I} \kappa \mathrm{B}$ proteins by using western blotting. Our results showed that the combination of mangiferin and each of the other anticancer drugs significantly suppressed the nuclear translocation of NF- $\kappa \mathrm{B}$ (Fig. 3). Further, we observed no changes in the levels of ERK1/2 and JNK1/2 phosphorylation (Fig. 4). These results indicated that the decrease in the combination of mangiferin and an anticancer drug induced cell viability was attributed to inhibition of the NF- $\mathrm{KB}$ pathway.

The combination of mangiferin and an anticancer drug increases the expression of p53 and Noxa and decreases the expression of XIAP, survivin, and Bcl-xL proteins. NF- $\mathrm{KB}$ is a nuclear factor known to activate the expression of genes involved in cell proliferation and cell survival (anti-apoptotic proteins and pro-apoptotic proteins). Therefore, we examined the expression of proteins involved in cell proliferation and cell survival by using western blotting. Our results showed that the combination of mangiferin and an anticancer drug upregulated the expression of p53 and Noxa and downregulated that of XIAP, survivin, and Bcl-xL proteins in comparison with mangiferin alone (Figs. 5 and 6). However, we observed no changes in the expression of cyclin D, cyclin E, p27, p21, Bcl-2, Bax, Bim, and PUMA proteins.

The combination of mangiferin and an anticancer drug causes the accumulation of cells in the sub-Gl phase of the cell cycle. p53 plays important roles in various phases of the cell cycle. Thus, we examined cell cycle regulation in IM9 cells treated with a combination of mangiferin and each of the other anticancer drugs by flow cytometry. Our results showed that the combined treatment increased the accumulation of cell population in the sub-G1 phase (Fig. 7). These results are indicative of apoptosis.

The combination of mangiferin and an anticancer drug induces apoptosis by activating caspase-3. We measured 
$\mathbf{A}$

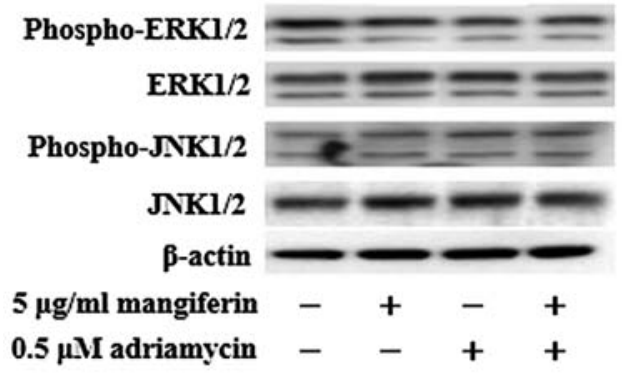

B

\section{Phospho-ERKl/2}

ERK1/2

Phospho-JNKl/2

JNK1/2

B-actin

$5 \mu \mathrm{g} / \mathrm{ml}$ mangiferin

$5 \mathrm{nM}$ vincristine
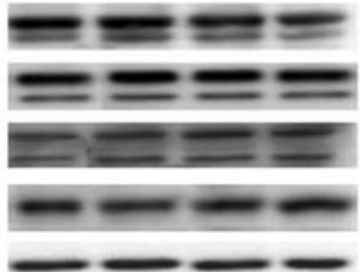

$-+-+$

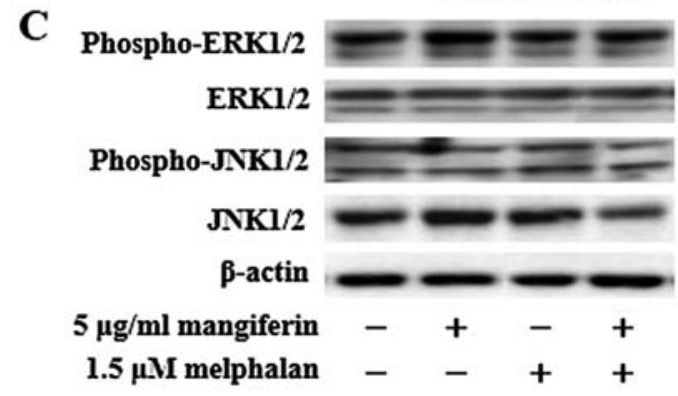

Figure 4. The combination of mangiferin and an anticancer drug do not change the levels of ERK1/2 and JNK1/2 phosphorylation. IM9 cells were treated with mangiferin $(5 \mu \mathrm{g} / \mathrm{ml})$ or $(\mathrm{A})$ adriamycin $(0.5 \mu \mathrm{M})$, (B) vincristine $(5 \mathrm{nM})$, and (C) melphalan $(1.5 \mu \mathrm{M})$, or a mixture of mangiferin with an anticancer drug for three days. The expression of phospho-ERK1/2, and phospho-JNK1/2 was detected using western blotting. The expression of ERK1/2, JNK1/2, and $\beta$-actin were used as internal controls.

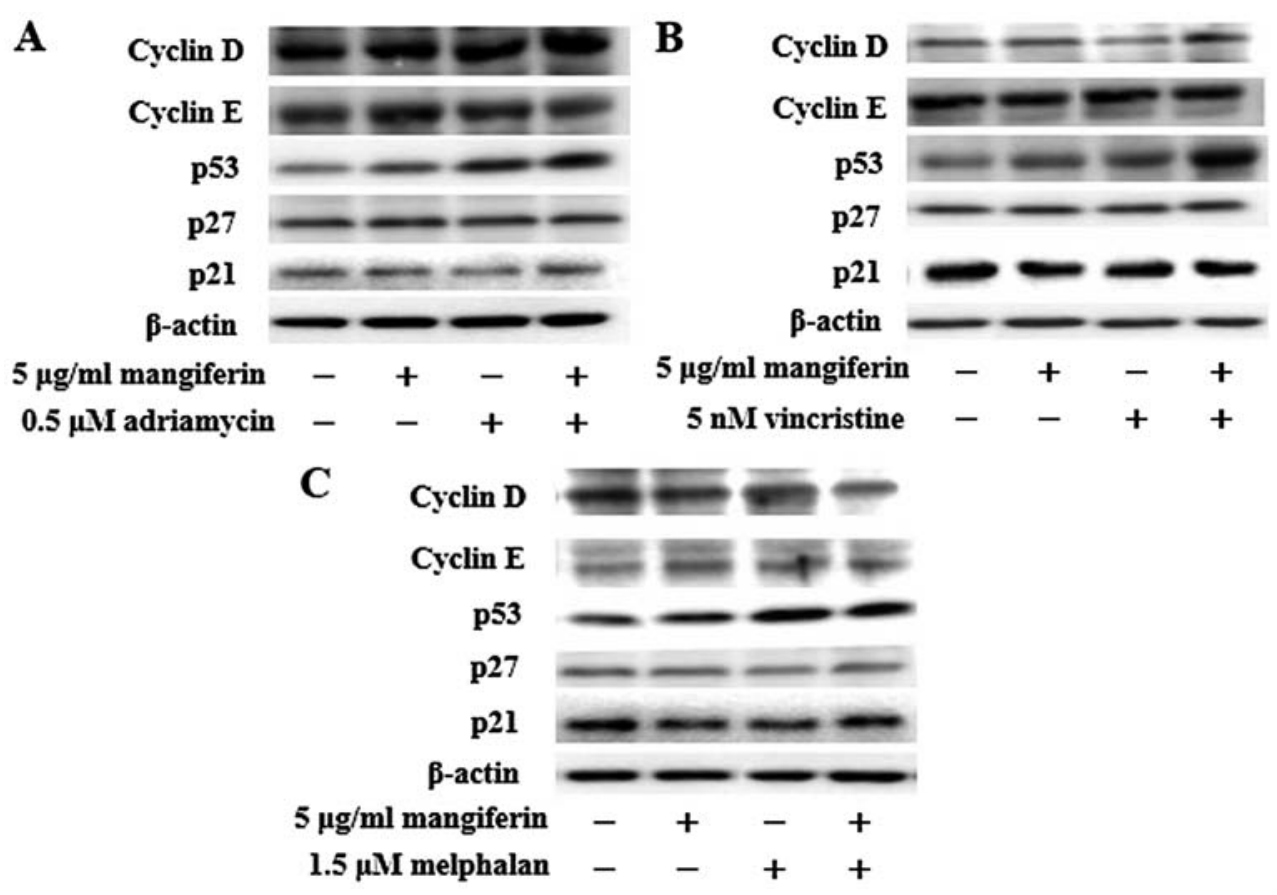

Figure 5. The combination of mangiferin and an anticancer drug increases the expression of p53. IM9 cells were treated with mangiferin $(5 \mu \mathrm{g} / \mathrm{ml})$ or $(\mathrm{A})$ adriamycin $(0.5 \mu \mathrm{M})$, (B) vincristine $(5 \mathrm{nM})$, and $(C)$ melphalan $(1.5 \mu \mathrm{M})$, or a mixture of mangiferin with an anticancer drug for three days. The expression of cyclin D, cyclin E, p53, p27, and p21 were detected using western blotting. The expression of $\beta$-actin was used as internal control.

apoptotic cells using the Muse ${ }^{\mathrm{TM}}$ Annexin V and Dead Cell Assay kit. IM9 cells were treated with a combination of mangiferin and each of the other anticancer drugs for two days. Our results showed that mangiferin increased the number of apoptotic cells in a concentration-dependent manner (Fig. 8A). Apoptosis is induced by an interaction between various initiator and effector caspases. Caspase-3 is a crucial effector of the apoptosis pathway. We investigated caspase-3 activation in IM9 cells treated with a combination of mangiferin and each of the other anticancer drugs by using the caspase-3/CPP32 fluorometric assay kit. The combination of mangiferin and an anticancer drug activated caspase-3 (Fig. 8B). These results showed that the combined treatment induced apoptosis by activating caspase- 3 . 


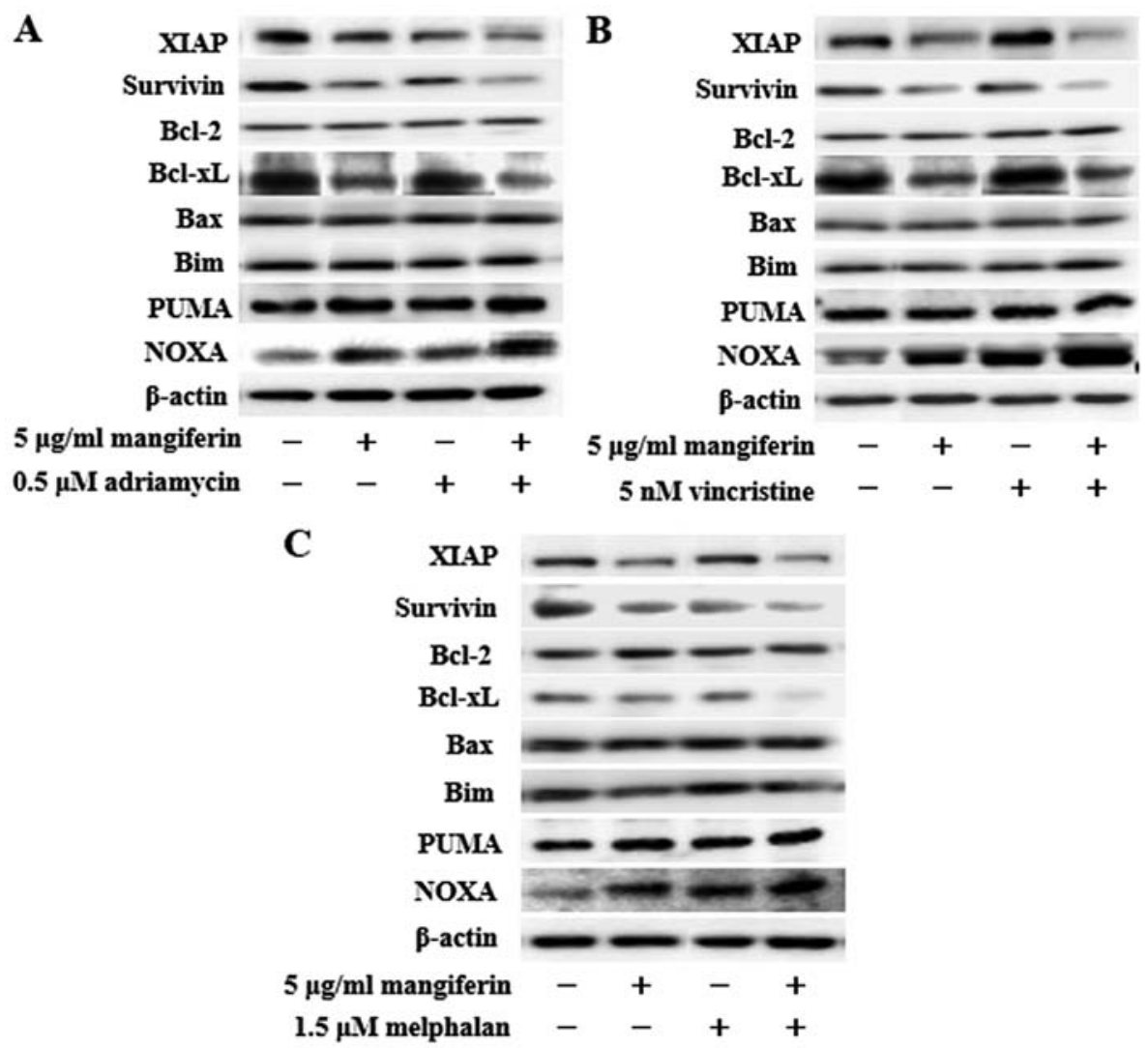

Figure 6. The combination of mangiferin and an anticancer drug increase the expression of Noxa, and decrease the expression of XIAP, survivin, and Bcl-xL proteins. IM9 cells were treated with mangiferin $(5 \mu \mathrm{g} / \mathrm{ml})$ or $(\mathrm{A})$ adriamycin $(0.5 \mu \mathrm{M})$, (B) vincristine $(5 \mathrm{nM})$, and $(\mathrm{C})$ melphalan $(1.5 \mu \mathrm{M})$, or a mixture of mangiferin with an anticancer drug for three days. The expression of XIAP, survivin, Bcl-2, Bcl-xL, Bax, Bim, PUMA, and Noxa were detected using western blotting. The expression of $\beta$-actin was used as internal control.
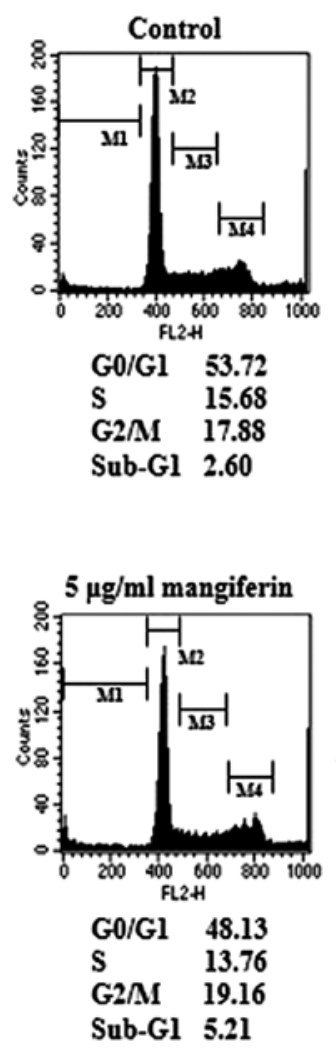

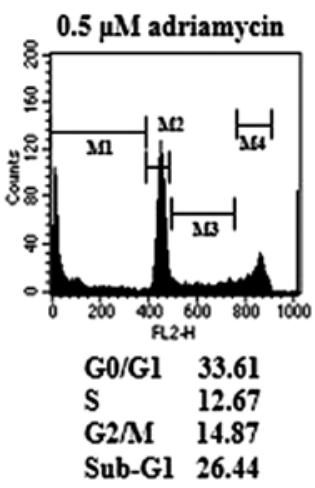

$5 \mu \mathrm{g} / \mathrm{ml}$ mangiferin

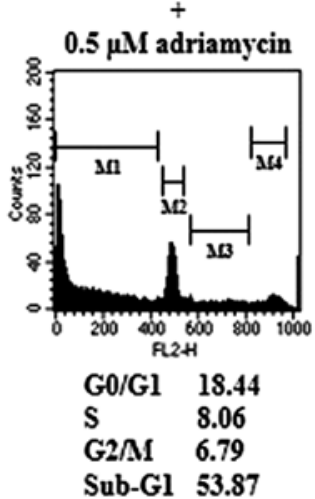

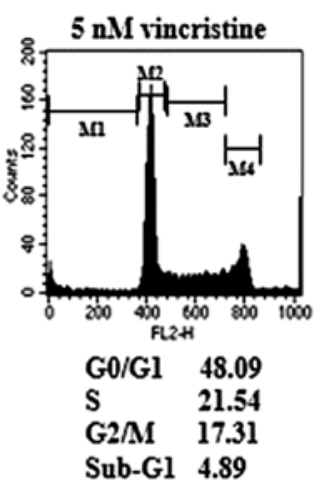

$5 \mu \mathrm{g} / \mathrm{ml}$ mangiferin

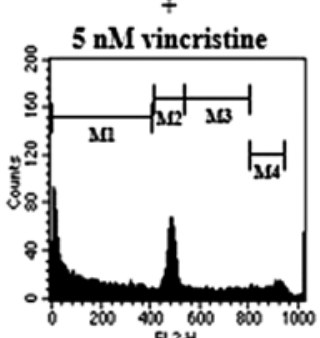

G0/Gl 23.3?

$\mathrm{S} \quad 11.65$

G2/M 8.35

Sub-Gl 48.39

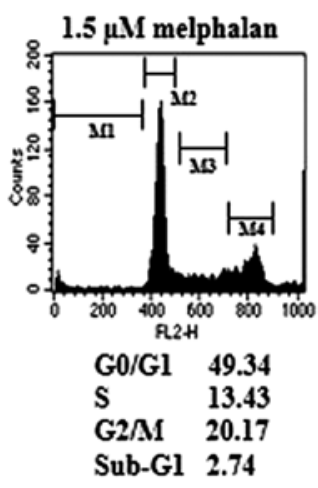

$5 \mu \mathrm{g} / \mathrm{ml}$ mangiferin

$1.5 \mu \mathrm{M}$ melphalan

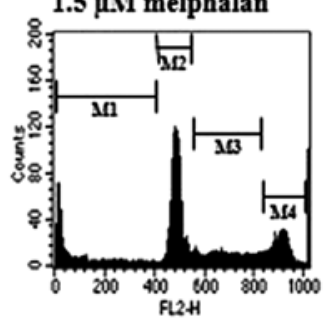

G0/G1 $\quad 41.23$

S $\quad 17.92$

G2/MI $\quad 17.37$

Sub-Gl 17.46

Figure 7. The combination of mangiferin and an anticancer drug causes the accumulation of the cells in the sub-G1 phase of the cell cycle. IM9 cells were treated with mangiferin $(5 \mu \mathrm{g} / \mathrm{ml})$ or adriamycin $(0.5 \mu \mathrm{M})$, vincristine $(5 \mathrm{nM})$, and melphalan $(1.5 \mu \mathrm{M})$, or a mixture of mangiferin with an anticancer drug for three days. Cell cycle distribution was analyzed at an hour after PI staining. 
A
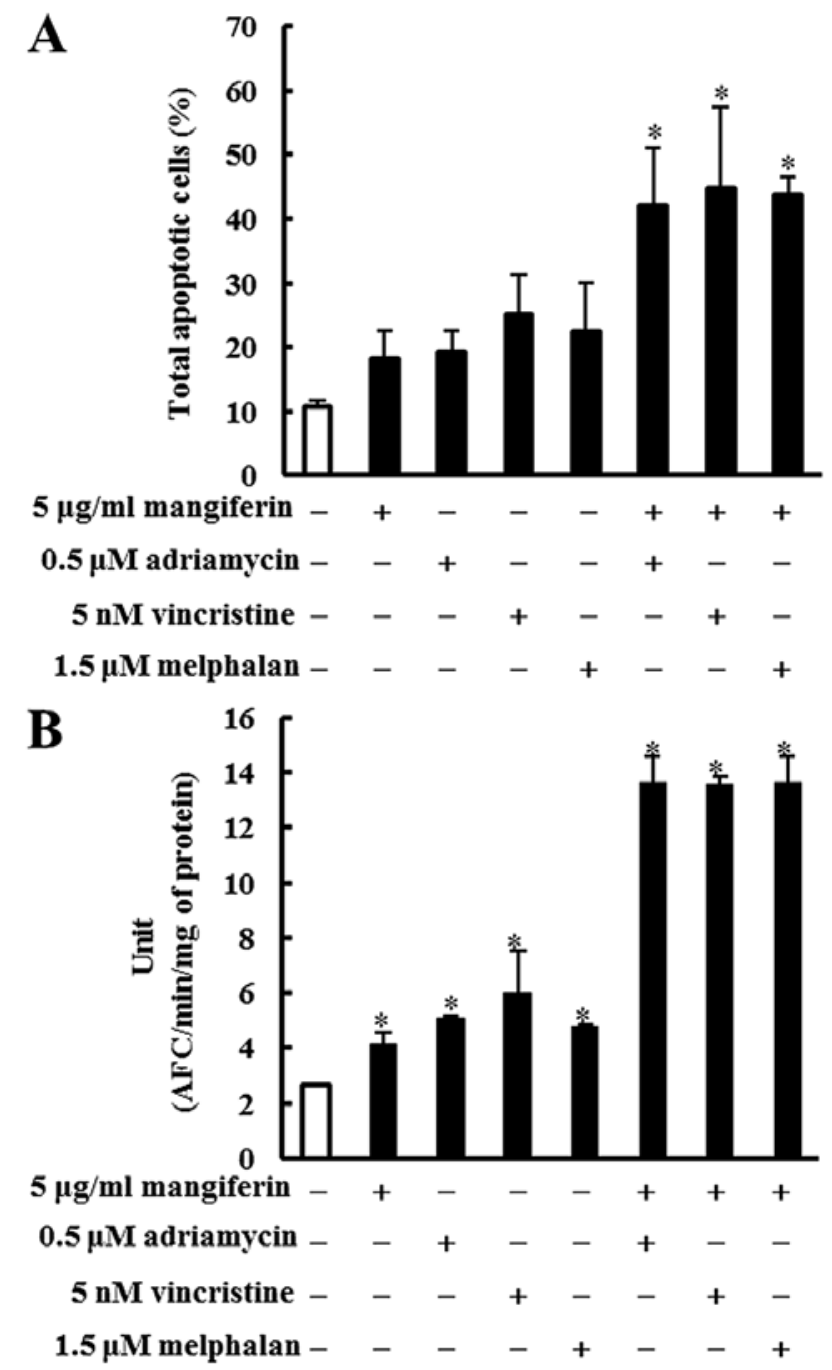

Figure 8 . The combination of mangiferin and an anticancer drug induces apoptosis by activating caspase-3. (A) IM9 cells were treated with mangiferin $(5 \mu \mathrm{g} / \mathrm{ml})$ or adriamycin $(0.5 \mu \mathrm{M})$, vincristine $(5 \mathrm{nM})$, and melphalan $(1.5 \mu \mathrm{M})$, or a mixture of mangiferin with an anticancer drug for two days. The number of apoptotic cells in IM9 cells was examined using the Muse Annexin V and Dead Cell Assay kit. (B) IM9 cells were treated with mangiferin $(5 \mu \mathrm{g} / \mathrm{ml})$ or adriamycin $(0.5 \mu \mathrm{M})$, vincristine $(5 \mathrm{nM})$, and melphalan $(1.5 \mu \mathrm{M})$, or a mixture of mangiferin with an anticancer drug for $36 \mathrm{~h}$. The activity of caspase- 3 induced by mangiferin in IM9 cells was examined using the caspase-3/CPP32 fluorometric assay kit. The results are expressed as the mean \pm standard deviation (SD) of four experiments. " $p<0.05$ compared with control.

\section{Discussion}

Despite the development of increasingly effective therapies, MM remains an incurable disease with an average survival of 3-5 years following diagnosis. In addition, most of the compounds used for MM treatment have side effects that limit their utility. Presumably, the side effects of these compounds could be decreased by reducing their dose and using them in combination with another drug (21). The nuclear factor $\kappa \mathrm{B}$ $(\mathrm{NF}-\kappa \mathrm{B})$ pathway plays a crucial role in the pathogenesis of MM $(22,23)$. Thus, inhibition of the NF- $\kappa B$ pathway is a potential target for the treatment of MM. We have previously shown that mangiferin induced apoptosis in AML cell lines via inhibition of the NF- $\kappa$ B pathway (20). Additionally, it was reported that mangiferin in combination with oxaliplatin counteract the development of resistance to oxaliplatin in colon cancer cells by reducing active NF- $\kappa \mathrm{B}$ (24). However, the effect of the combination of mangiferin and conventional anticancer drugs in MM cell lines remain to be clarified. In particular, the molecular mechanism has not been elucidated thus far. In this study, we examined the effect of the combination of mangiferin and conventional anticancer drugs in MM cell lines.

We showed that mangiferin, adriamycin, vincristine, and melphalan decrease the viability of MM cell lines. The combination of mangiferin and each of the above-mentioned anticancer drugs significantly reduced the viability of the MM cell line in comparison with each of these drugs used alone. Furthermore, our results showed that the combination treatment significantly suppressed the nuclear translocation of NF- $\kappa$ B. However, we observed no changes in the levels of ERK1/2 and JNK1/2 phosphorylation. In agreement with previous reports, constitutive activation of $\mathrm{NF}-\kappa \mathrm{B}$ promoted multiple myeloma cell growth and survival, and the $N F-\kappa B$ inhibitor dimethyl fumarate induced apoptosis in MM cell lines $(15,25)$. In addition, other studies showed that celastrol induces chemosensitization through downregulation of $\mathrm{NF}-\kappa \mathrm{B}$ in MM cell lines (17). These results indicate that the combination of mangiferin and other anticancer drugs exert their effects on MM through downregulation of NF- $\kappa \mathrm{B}$ pathway.

$\mathrm{NF}-\kappa \mathrm{B}$ initiates the transcriptional activation of prosurvival genes and proliferation-promoting genes (26). We observed that the combination of mangiferin and each of the other anticancer drugs significantly increased the expression of p53 and Noxa and decreased the expression of XIAP, survivin, and $\mathrm{Bcl}-\mathrm{xL}$, proteins. In addition, the combination treatment caused the induction of apoptosis, activation of caspase-3 and the accumulation of the cells in the sub-G1 phase of the cell cycle. The tumor suppressor p53 induces apoptosis by transactivation of its downstream apoptotic regulators such as Noxa (27). Survivin, a member of the inhibitor of apoptosis protein family, protects cells from caspase-dependent apoptotic pathways. Survivin overexpression has been reported in various hematopoietic and solid cancers (28-30). XIAP is the most potent endogenous direct inhibitor of caspases and is thus considered a key physiological regulator of cell death. MM cells express high levels of XIAP regulated by the NF- $\kappa \mathrm{B}$ pathway (31). The Bcl-2 family member Bcl-xL is an antiapoptotic protein; $\mathrm{Bcl}-\mathrm{xL}$ overexpression has been reported in MM cell lines $(32,33)$. These results suggest that the combination of mangiferin and an anticancer drug induces apoptosis by increasing the expression of p53 and Noxa and decreasing that of XIAP, survivin, and Bcl-xL proteins via inhibition of the NF- $\kappa \mathrm{B}$ pathway.

In conclusion, our results showed that the combination of mangiferin and an anticancer drug decreased the viability of $\mathrm{MM}$ cell lines in comparison with each of these drugs used separately. The decrease in the combination of mangiferin and an anticancer drug induced cell viability was attributed to the induction of apoptosis, activation of caspase-3, and the accumulation of the cells in the sub-G1 phase of the cell cycle via inhibition of nuclear translocation of NF- $\kappa$ B. Importantly, $40 \%$ of multiple myeloma patients show constitutive activation of the NF- $\kappa \mathrm{B}$ pathway. Our findings showed that the combina- 
tion of mangiferin and an anticancer drug selectively inhibited the NF- $\kappa \mathrm{B}$ pathway without inhibiting other signaling factors. In addition, we found that mangiferin enhanced the effect of conventional anticancer drugs (adriamycin, vincristine, and melphalan) commonly used in multiple myeloma treatment. Our results provided evidence of the potential of the combination of mangiferin and an anticancer drug as a new regime for the treatment of MM.

\section{Acknowledgements}

This study was supported in part by a Grant-in-Aid for Scientific Research (C) from the Japan Society for the Promotion of Science (JSPS) and by Ministry of Education, Culture, Sports, Science, and Technology (MEXT)-Supported Program for the Strategic Research Foundation at Private Universities, 2014-2018.

\section{References}

1. Raab MS, Podar K, Breitkreutz I, Richardson PG and Anderson KC: Multiple myeloma. Lancet 374: 324-339, 2009.

2. Bladé J, Cibeira MT and Rosiñol L: Novel drugs for the treatment of multiple myeloma. Haematologica 95: 702-704, 2010.

3. Rajkumar SV: Treatment of multiple myeloma. Nat Rev Clin Oncol 8: 479-491, 2011

4. Wang X, Zhang M, Wang M, He P, Liu X, Chen L, Xi J, Wang M, Li J, Liu H, et al: Arsenic trioxide combined with VCMP or VAD chemotherapy in patients with refractory or relapsed multiple myeloma in a single institution of China. Indian J Hematol Blood Transfus 30: 259-264, 2014.

5. Paramore A and Frantz S: Bortezomib. Nat Rev Drug Discov 2: 611-612, 2003.

6. Sethi G, Sung B and Aggarwal BB: Nuclear factor-kappaB activation: From bench to bedside. Exp Biol Med (Maywood) 233: 21-31, 2008.

7. Tsubaki M, Takeda T, Ogawa N, Sakamoto K, Shimaoka H, Fujita A, Itoh T, Imano M, Ishizaka T, Satou T, et al: Overexpression of survivin via activation of ERK1/2, Akt, and NF- $\kappa \mathrm{B}$ plays a central role in vincristine resistance in multiple myeloma cells. Leuk Res 39: 445-452, 2015.

8. Cormier F, Monjanel H, Fabre C, Billot K, Sapharikas E, Chereau F, Bordereaux D, Molina TJ, Avet-Loiseau H and Baud V: Frequent engagement of RelB activation is critical for cell survival in multiple myeloma. PLoS One 8: e59127, 2013.

9. Karin M and Greten FR: NF-kappaB: Linking inflammation and immunity to cancer development and progression. Nat Rev Immunol 5: 749-759, 2005.

10. Ma C, Zuo W, Wang X, Wei L, Guo Q and Song X: Lapatinib inhibits the activation of NF- $\mathrm{KB}$ through reducing phosphorylation of I $\mathrm{B}-\alpha$ in breast cancer cells. Oncol Rep 29: 812-818, 2013.

11. Hideshima T, Ikeda H, Chauhan D, Okawa Y, Raje N, Podar K, Mitsiades C, Munshi NC, Richardson PG, Carrasco RD, et al: Bortezomib induces canonical nuclear factor-kappaB activation in multiple myeloma cells. Blood 114: 1046-1052, 2009.

12. Hayden MS and Ghosh S: Shared principles in NF-kappaB signaling. Cell 132: 344-362, 2008.

13. Panwalkar A, Verstovsek S and Giles F: Nuclear factor-kappaB modulation as a therapeutic approach in hematologic malignancies. Cancer 100: 1578-1589, 2004.

14. Joyce D, Albanese C, Steer J, Fu M, Bouzahzah B and Pestell RG: NF-kappaB and cell-cycle regulation: The cyclin connection. Cytokine Growth Factor Rev 12: 73-90, 2001.

15. Tsubaki M, Ogawa N, Takeda T, Sakamoto K, Shimaoka H, Fujita A, Itoh T, Imano M, Satou T and Nishida S: Dimethyl fumarate induces apoptosis of hematopoietic tumor cells via inhibition of NF- $\kappa \mathrm{B}$ nuclear translocation and down-regulation of Bcl-xL and XIAP. Biomed Pharmacother 68: 999-1005, 2014.

16. Olaku O and White JD: Herbal therapy use by cancer patients: A literature review on case reports. Eur J Cancer 47: 508-514, 2011.
17. Jeong SJ, Koh W, Kim B and Kim SH: Are there new therapeutic options for treating lung cancer based on herbal medicines and their metabolites? J Ethnopharmacol 138: 652-661, 2011.

18. Wang LH, Li Y, Yang SN, Wang FY, Hou Y, Cui W, Chen K, Cao Q, Wang S, Zhang TY, et al: Gambogic acid synergistically potentiates cisplatin-induced apoptosis in non-small-cell lung cancer through suppressing NF- $\mathrm{\kappa B}$ and MAPK/HO-1 signalling. Br J Cancer 110: 341-352, 2014.

19. Luo F, Lv Q, Zhao Y, Hu G, Huang G, Zhang J, Sun C, Li X and Chen K: Quantification and purification of mangiferin from Chinese Mango (Mangifera indica L.) cultivars and its protective effect on human umbilical vein endothelial cells under $\mathrm{H}(2) \mathrm{O}(2)$ induced stress. Int J Mol Sci 13: 11260-11274, 2012.

20. Shoji K, Tsubaki M, Yamazoe Y, Satou T, Itoh T, Kidera Y, Tanimori Y, Yanae M, Matsuda H, Taga A, et al: Mangiferin induces apoptosis by suppressing Bcl-xL and XIAP expressions and nuclear entry of NF-KB in HL-60 cells. Arch Pharm Res 34: 469-475, 2011.

21. Slawinska-Brych A, Zdzisinska B, Mizerska-Dudka M and Kandefer-Szerszen M: Induction of apoptosis in multiple myeloma cells by a statin-thalidomide combination can be enhanced by p38 MAPK inhibition. Leuk Res 37: 586-594, 2013.

22. Kannaiyan R, Hay HS, Rajendran P, Li F, Shanmugam MK, Vali S, Abbasi T, Kapoor S, Sharma A, Kumar AP, et al: Celastrol inhibits proliferation and induces chemosensitization through down-regulation of NF- $\mathrm{KB}$ and STAT3 regulated gene products in multiple myeloma cells. Br J Pharmacol 164: 1506-1521, 2011.

23. Tsubaki M, Komai M, Itoh T, Imano M, Sakamoto K, Shimaoka H, Ogawa N, Mashimo K, Fujiwara D, Takeda T, et al: Inhibition of the tumour necrosis factor-alpha autocrine loop enhances the sensitivity of multiple myeloma cells to anticancer drugs. Eur J Cancer 49: 3708-3717, 2013.

24. du Plessis-Stoman D, du Preez J and van de Venter M: Combination treatment with oxaliplatin and mangiferin causes increased apoptosis and downregulation of $\mathrm{NF \kappa B}_{\text {in cancer cell }}$ lines. Afr J Tradit Complement Altern Med 8: 177-184, 2011.

25. Trocoli A and Djavaheri-Mergny M: The complex interplay between autophagy and NF- $\kappa \mathrm{B}$ signaling pathways in cancer cells. Am J Cancer Res 1: 629-649, 2011.

26. DiDonato JA, Mercurio F and Karin M: NF- $\kappa B$ and the link between inflammation and cancer. Immunol Rev 246: 379-400, 2012.

27. Zhu HJ, Liu L, Fan L, Zhang LN, Fang C, Zou ZJ, Li JY and $\mathrm{Xu} \mathrm{W}$ : The $\mathrm{BH} 3$-only protein Puma plays an essential role in p53-mediated apoptosis of chronic lymphocytic leukemia cells. Leuk Lymphoma 54: 2712-2719, 2013.

28. Tsubaki M, Satou T, Itoh T, Imano M, Komai M, Nishinobo M, Yamashita M, Yanae M, Yamazoe Y and Nishida S: Overexpression of MDR1 and survivin, and decreased Bim expression mediate multidrug-resistance in multiple myeloma cells. Leuk Res 36: 1315-1322, 2012.

29. Tsubaki M,Komai M,Itoh T,Imano M, Sakamoto K, Shimaoka H, Takeda T, Ogawa N, Mashimo K, Fujiwara D, et al: By inhibiting Src, verapamil and dasatinib overcome multidrug resistance via increased expression of Bim and decreased expressions of MDR1 and survivin in human multidrug-resistant myeloma cells. Leuk Res 38: 121-130, 2014.

30. Markovic O, Marisavljevic D, Cemerikic-Martinovic V, Martinovic T, Filipovic B, Stanisavljevic D, Zivković R, Hajder J, Stanisavljevic N and Mihaljevic B: Survivin expression in patients with newly diagnosed nodal diffuse large B cell lymphoma (DLBCL). Med Oncol 29: 3515-3521, 2012.

31. Desplanques G, Giuliani N, Delsignore R, Rizzoli V, Bataille R and Barillé-Nion S: Impact of XIAP protein levels on the survival of myeloma cells. Haematologica 94: 87-93, 2009.

32. Lin J, Wu Y, Yang D and Zhao Y: Induction of apoptosis and antitumor effects of a small molecule inhibitor of Bcl-2 and $\mathrm{Bcl}-\mathrm{xl}$, gossypol acetate, in multiple myeloma in vitro and in vivo. Oncol Rep 30: 731-738, 2013.

33. Xu L, Yang D, Wang S, Tang W, Liu M, Davis M, Chen J, Rae JM, Lawrence T and Lippman ME: (-)-Gossypol enhances response to radiation therapy and results in tumor regression of human prostate cancer. Mol Cancer Ther 4: 197-205, 2005. 